\title{
Reflexões Da Teoria Cognitiva De Vergnaud Sobre O Ensino De Matemática: À Luz De Registros Semióticos
}

\section{Reflections On Vergnaud's Cognitive Theory On Mathematics Teaching: In The Light Of Semiotic Records}

\author{
Raimundo Luna Neres \\ Universidade Federal do Maranhão - (UFMA) \\ Universidade CEUMA - (UNICEUMA) \\ Eliziane Rocha Castro
}

Secretaria Municipal de Educação de Raposa/MA

Antonio Luiz de Oliveira Barreto

Universidade Estadual do Ceará - (UECE)

Fernanda Gabriele Santos Silva

Universidade CEUMA - (UNICEUMA)

\begin{abstract}
Resumo
Apresenta-se neste artigo uma pesquisa com enfoque didático-pedagógico em isomorfismos de medidas baseada na teoria dos campos conceituais de Vergnaud e com aporte na teoria dos registros semióticos. O objetivo foi analisar o uso didático destas teorias na operacionalização das atividades matemáticas pelas professoras do quinto ano do ensino fundamental. Trata-se de uma pesquisa qualitativa realizada numa escola municipal da cidade de Raposa/MA, desenvolvida em sessões reflexivas da teoria de Vergnaud. Sendo uma destinada às reflexões teóricas sobre a teoria vergnausiana e as demais destinadas à elaboração/resolução de atividades matemáticas, usando-se registros semióticos. Observou-se que as professoras tiveram compreensão de todas as classes pertencentes à categoria de isomorfismo de medidas, assim como da elaboração/resolução, usando registros semióticos, com predominância da multiplicação. Mas, em alguns casos de divisão, os enunciado dos problemas não se tornava claro, podendo ensejar erros de interpretação. Entretanto, reconheceram que essa metodologia permite usar diferentes registros para uma mesma atividade, o que contribui pedagogicamente para a aprendizagem das matemáticas.
\end{abstract}

Palavras-chave: Registros semióticos. Isomorfismos de medidas. Teoria de Vergnaud. Aprendizagem das matemáticas.

\begin{abstract}
This article presents a research with didactic-pedagogical approach in measures isomorphisms based on the theory of the conceptual fields of Vergnaud and with contribution in the theory of semiotic registers. The objective was to analyze the didactic use of these theories in the operationalization of mathematical activities by the teachers of the fifth year of elementary school. This is a qualitative research carried out at a municipal school in the city of Raposa / MA, developed in reflexive sessions of Vergnaud's theory. One is destined to the theoretical reflections on the vergnausian theory and the others destined to the elaboration / resolution of mathematical activities, using
\end{abstract}


semiotic registers. It was observed that the teachers had an understanding of all classes belonging to the category of measures isomorphism, as well as the elaboration / resolution, using semiotic registers, with a predominance of multiplication. But in some cases of division, the statements of the problems were not clear and could lead to errors of interpretation. However, they recognized that this methodology allows the use of different registers for the same activity, which contributes pedagogically to the learning of mathematics.

Keywords: Semiotic records. Measurement isomorphisms. Theory of Vergnaud. Learning mathematics.

\section{Introdução}

Neste artigo discute-se a formação de professoras - pedagogas do quinto ano do ensino fundamental quanto a aplicação de isomorfismos de medidas baseado na teoria dos campos conceituais de Vergnaud (2009), na elaboração/resolução de atividades multiplicativas como pressupostos para aprendizagem das matemáticas com aporte na teoria dos registros de representação semiótica de Duval (2007).

Esta formação implica a preparação do profissional de ensino a tomar ciência de um conjunto de conhecimentos teóricos e práticos para serem desenvolvidos na sua docência. Pois, considera-se que, durante a formação da licenciatura, possivelmente, não vivenciaram experiências formativas de elaboração de problemas, baseados nos campos conceituais de Vergnaud, principalmente usando registros de representação semiótica, fundamentos que podem ajudar a enfrentar desafios presentes em aulas de matemática e facilitar a aprendizagem.

As abordagens teóricas de ensino e, de aprendizagem, às vezes, são feitas de forma interacionista, em que o professor é o protagonista do processo de aprendizagem dos alunos, tornando-se, portanto, o mediador entre eles e o conhecimento, empreendendo, assim, ações sistemáticas para atingir os objetivos educacionais propostos.

Nessa direção, a elaboração/resolução de atividades matemáticas dependerá dos atos de mediação do docente. Assim, quais seriam as competências das professoras na elaboração/resolução de atividades multiplicativas da classe de isomorfismo de medidas, usando registros semióticos?

Competências essas que na presente investigação possui estatuto teórico no aporte vergnausiano sendo um conceito pragmático compreendido como eskemas evocados em situações específicas com certo automatismo e eficiência (OTERO, 2014) ou como define Philippe Perrenoud (2000, p.15) trata-se da "capacidade de mobilizar diversos recursos cognitivos para enfrentar um tipo de situação".

Para responder tais problemas buscou-se um olhar analítico sobre as características das situações-problema elaboradas pelas professoras. diante disso, optou-se por analisar as 
competências das professoras do $5^{\circ}$ ano do ensino fundamental na elaboração de situaçõesproblema multiplicativos, elaborados à luz de registros semióticos, antes e após a participação em sessões reflexivas conduzidas à luz da teoria de Vergnaud, sendo este o fator fulcral da presente pesquisa que tem sua importância exaltada pela possibilidade de mitigar a superficialidade do conhecimento sobre o desenvolvimento de conceitos matemáticos através da realização de sessões reflexivas que visam romper com as práticas que estão arraigadas no cotidiano escolar, práticas que espedaçam o saber podendo gerar alguma ignorância e cegueira, ainda que produzam algum conhecimento (GASPARIN, 2005). Como exemplo de tais práticas, cite-se o protagonismo dos algoritmos convencionais e da memorização das tabuadas no ensino das operações de multiplicação e divisão nas aulas de matemática, que são conduzidas por um percurso que se inicia pela demonstração dos procedimentos de resolução de cada algoritmo e termina na aplicação de exercícios repetitivos.

Esta pesquisa justifica-se, pois, nesse período, o professora trabalha a construção e ampliação dos conceitos relacionados ao campo conceitual das estruturas multiplicativas. Se nesse estágio não ocorrer a apropriação dessas estruturas, isso poderá comprometer a aprendizagem dos alunos e fragilizar a compreensão e poderá refletir-se em insucesso escolar.

Para Moretti (2007), em discussões sobre ensino e aprendizagem de conceitos em matemática, uma preocupação, frequentemente levantada, é de como transformar objetos de pesquisa em objetos de ensino. Essa preocupação é fruto do papel das representações semióticas e da noção de congruência semântica na aprendizagem da matemática. No entanto, segundo Neres (2017) nem sempre a semelhança semiótica e semântica é suficiente para satisfazer a continuidade do discurso matemático. Neste caso, deve-se dar uma segunda dimensão ao objeto matemático que torne necessário ou não a se recorrer a uma terceira maneira de expressão do objeto.

Para se entender a expressão escrita e que satisfaça as mesmas condições, uma semelhança semiótica ou semântica de cada uma das declarações deve estar ligada ao ato da produção intencional da pergunta e do registro que sucede ao enunciado. Portanto, não há expansão discursiva de um enunciado que não se baseie na combinação de uma semelhança semiótica ou semântica e de uma semelhança interna ou externa.

Por outro lado, o insucesso escolar dos alunos em matemática, conforme dados divulgados pelo Inep, pouco evoluíram nos anos iniciais e finais do ensino fundamental, uma vez que do total de alunos avaliados, nessa pesquisa, só aproximadamente 39\% demonstraram aprendizagem adequada (INEP/PROVA BRASIL, 2015). Baseado nesse contexto, as 
professoras - pedagogas estão sendo bem preparadas para o ensino das matemáticas?

Trata-se, então de uma investigação qualitativa de caráter interventivo didático pedagógico, com sete professoras do quinto ano do ensino fundamental de uma escola pública do município de Raposa/MA, em elaboração/resolução de atividades matemáticas à luz de registros semióticos. As informações da pesquisa constituem-se tanto dos registros escritos dessas docentes que dela participaram quanto também das anotações dos pesquisadores que realizaram a intervenção didática.

O caminho metodológico consistiu em vivenciar com as professoras, no exercício da docência, como ocorreria a compreensão conceitual e habilidades ao elaborarem/resolverem problemas multiplicativos da classe de isomorfismos de medidas, usando-se representações semióticas. Os dados dessas observações foram registrados pelos pesquisadores para posterior análise.

Segundo Duval (2007), não há aprendizagem em matemática, se o discente não distinguir um objeto de sua representação, como por exemplo, não deve confundir os números, com as suas representações, visto que uma sentença em matemática pode ser representada de várias maneiras.

Duval (2011) afirma ainda que uma variedade de representações semióticas, deve ser utilizada em atividades de problemas multiplicativos, pois elas são necessárias para o desenvolvimento da compreensão matemática.

Portanto, a apropriação dos conceitos relativos à classe de problemas multiplicativos e das práticas de ensino desses conceitos é condição necessária na formação continuada dessas professoras. Justifica-se, dessa forma, pesquisar como resolver problemas de isomorfismo de medidas, que, em conjunto com os registros semióticos, mobilizam a aprendizagem das professoras, relativamente a essas operações e ao modo de ensiná-las mediante essas teorias.

Dessa forma, a mobilização de representações de registros semióticos deve ocorrer entre mudanças de representações - conversão e no desenvolvimento operacional no próprio registro - tratamento. Segundo Duval (2009), quando se resolve uma sentença matemática, sem mudar a forma com que foi elaborada, o que se está fazendo é uma operação de tratamento, como se pode observar neste enunciado: calcular o valor da expressão numérica: $(10 \times 4) \div 8=$ ? e quando se muda de uma forma de representação para outra, está fazendo-se uma conversão, a exemplo de representar, através de registros numéricos, o texto: Maria comprou uma boneca por cinquenta e dois reais, quanto custariam três dessas mesmas bonecas?

Logo, o uso de representações semióticas, na elaboração/resolução de atividades 
pertencentes à classe de isomorfismo de medidas é importante no sentido de diminuir com determinadas práticas que são trabalhadas no cotidiano escolar (GASPARIN, 2005), haja vista que a utilização, em demasia, nas aulas de matemática, dos algoritmos convencionais e das tabuadas em operações matemáticas não leva o aluno a desenvolver seu raciocínio.

\title{
Investigação Teórica
}

Para Vergnaud (2012) alguns professores esquecem de demonstrar aos discentes como o conhecimento matemático é útil e funcional e prejudica os alunos quando deixam de trabalhar as questões formais e formulam problemas desconectados com a realidade do aluno. Isso pode refletir na concepção de alguns estudantes em considerar a matemática como uma disciplina de mais difícil aprendizagem do que as outras disciplinas. Ele afirma, ainda, que o docente deverá intervir como mediador do conhecimento, propondo situações de aprendizagem nas quais os alunos terão oportunidade de desenvolver novas formas de organizar suas atividades.

Bruner (1978) considera que a mediação permite ao professor trabalhar estratégias de resolução com seus alunos de modo a proporcionar-lhes a produção de suas próprias heurísticas. Por outro lado, o que se constata é que, normalmente, as dificuldades enfrentadas pelos alunos na compreensão da matemática são originadas,

\begin{abstract}
Dos processos epistemológicos particular do conhecimento matemático, e não somente nas questões de organização pedagógica das atividades. Para que os alunos possam efetivamente compreender a matemática, ou que ela contribua para a sua formação, é preciso desenvolver outro tipo de funcionamento cognitivo que o praticado nas outras disciplinas. Para ensinar é preciso se ter consciência dos processos cognitivos específicos que requer o pensamento matemático (DUVAL, 2011, p. 8-9).
\end{abstract}

Portanto, para se produzir conhecimento matemático, segundo (VALE; PIMENTEL E BARBOSA, 2015), é preciso existir uma relação clara e consistente entre a compreensão dos conceitos matemáticos e o desenvolvimento cognitivo. Essa prática poderá tornar-se mais substantiva para o desenvolvimento dos alunos.

Em relação à classe de isomorfismo de medidas, nosso foco de investigação, a situação é compreendida como um conjunto de tarefas que moldam o conhecimento, na medida em que, gradualmente, essa classe é dominada (OTERO, 2010). Dessa forma, o domínio de uma situação requer conhecimento de conceitos, por isso esse confronto é essencial na formação do conceito.

Em geral, conceitos são ideias gerais e abstratas originárias de uma área específica do conhecimento na qual a generalidade e a abstração somente serão compreendidas pelos sujeitos 
através de um movimento evolutivo, em longo prazo, daí sua significação necessitar de sua aplicação em diferentes situações (VERGNAUD, 1993).

Entretanto, simbolicamente, o conceito também pode ser representado por $\mathrm{c}=(\mathrm{s}, \mathrm{i}, \mathrm{r})$, de modo que: $\mathrm{s}=$ conjunto de situações, $\mathrm{i}=$ conjunto de invariantes operatórios e $\mathrm{r}=$ conjunto das representações simbólicas (MAGINA et al., 2001).

Dessa forma, cada um dos conjuntos que compõe um conceito possui igual relevância no âmbito da teoria dos campos conceituais. Não é possível falar de construção de um conceito, sem se referir à importância das diversas situações, dos invariantes operatórios que contribuíram para que o sujeito fizesse a análise da situação com vistas a dominá-la e sem pontuar os procedimentos para lidar com a situação bem como as formas de representá-los.

Este estudo assenta-se nas estruturas multiplicativas que permitem analisar as situações cujo tratamento implica uma ou várias multiplicações e divisões dando origem a variados casos de conteúdo das matemáticas em particular o de proporção simples (GITIRANA et al., 2014; VERGNAUD, 1996).

Segundo os princípios vergnausianos, para compreensão da multiplicação e da divisão, exige-se dos alunos conhecimento dos números, de sua simbolização e de representações de maneira mais abrangente do que no caso da adição e subtração. As operações envolvendo multiplicação e divisão requerem a compreensão de novos significados dos números e uma nova coleção de invariantes relacionados com estas operações.

Gitirana et al (2014) destacam que há uma continuidade entre as operações de adição e multiplicação, no que tange à estrutura; não obstante, é diferente em relação aos significados, sobretudo porque a adição envolve uma relação ternária e grandezas iguais, enquanto a multiplicação envolve, em sua maioria, relações quaternárias.

Em geral, no ensino fundamental a multiplicação é trabalhada como uma adição repetida, essa forma de multiplicação provavelmente apareceu muito cedo na humanidade, pois segundo Wall (2014), só por volta de 1650 a.C., foi que os métodos de multiplicação começaram a aparecer no registro histórico.

Por outro lado, é mais difícil trabalhar a multiplicação com a ideia de combinação de possibilidades, como por exemplo, descobrir a quantidade de maneiras diferentes de se vestir combinando três calças com cinco camisas. Ou ainda, a multiplicação por decomposição, em que se decompõem uma ou as duas parcelas da multiplicação. Como por exemplo, para efetuar o produto $12 \times 14$, pode-se fazer a decomposição das parcelas, ou seja, $12=10+2$ e $14=$ $10+4$. Ou ainda $(10+2) \cdot(10+4)=10 \cdot 10+10 \cdot 4+2 \cdot 10+2 \cdot 4$. 
No entanto, nesta pesquisa tomou-se por base a teoria de Vergnaud (2009), onde ele apresenta duas categorias para o estudo do campo conceitual multiplicativo: a do isomorfismo de medidas (relação quaternária) e a do produto de medidas (relação ternária). As estruturas multiplicativas comportam uma relação quaternária, como no caso da proporcionalidade, "onde a multiplicação relaciona-se a dois conjuntos e quatro medidas, sendo três conhecidas e uma a ser encontrada através de operações matemáticas", (PESSOA; BORBA, 2009, p.113).

Nessa pesquisa, trabalhou-se com elaboração/resolução de atividades multiplicativas (relação quaternária), isto é: com multiplicação e divisão do tipo 1 (divisão partitiva) e do tipo 2 (divisão quotitiva), (VERGNAUD, 2009).

\section{Caminho Metodológico}

Para responder a essa investigação, a teoria de Raymond Duval foi aplicada para entender os discursos que poderiam estar associados a compreensão da matemática praticada pelas professoras no contexto escolar ou da sequências dos materiais didáticos utilizados pelos pesquisadores e professoras. Ou seja, teve como princípio estudar possíveis articulações entre os conhecimentos matemáticos vinculados ao isomorfismo de medidas, multiplicação e divisão, em relação as variações metodológicas de ensino usadas em sala de aula.

Das escolas onde os sujeitos dessa pesquisa exercem as suas atividades didáticas, 290 alunos fizeram a prova brasil 2015, e desses, apenas 20\% tiveram aproveitamento suficiente em matemática; $45 \%$, pouco aprendizado; e 35\%, quase nenhum aprendizado (esses dados foram informados pelas secretarias das escolas pesquisadas, 2016). Este resultado constituiu-se motivo para o desenvolvimento desta pesquisa, pois se acredita proporcionar aos participantes uma nova maneira de ver e de ensinar matemática, visando à melhoria do desempenho escolar dos alunos.

A sequência didática para a construção do corpus da pesquisa foi feita através de sessões reflexivas, realizadas em outubro de 2016, com duração de 15 horas, distribuídas em cinco momentos, conduzidas à luz da teoria cognitivista vergnausiana e dos registros de representação semiótica, para que pudéssemos analisar as competências das professoras na elaboração/resolução de sentenças multiplicativas.

No primeiro momento, trabalhou-se sobre a identificação de tipos de problemas: envolvendo multiplicação, divisão ou ambas as estruturas, suas características e relações enredadas à luz da teoria dos campos conceituais. Depois, tratou-se das representações 
matemáticas, observando onde ocorreriam as conversões e tratamentos dos registros semióticos envolvidos de partida e de chegada, enfocando e observando as estratégias de elaboração e de resolução, usando a mudança de um registro para outro registro e as operações de tratamento necessárias para construir a resposta requerida. Segundo Neres (2017), essas operações são necessárias para estabelecer uma conexão entre a forma de enunciado de partida e de chegada.

Todavia, o ensino das matemáticas nos anos iniciais da educação básica, em geral, não é desenvolvido com o rigor que a matemática exige. Para Curi (2006), isso ocorre em função da superficialidade com que alguns pedagogos conhecem determinados assuntos da matemática, bem como de conhecimentos didáticos e curriculares a ela relacionados. Esse desconhecimento, em geral, influi em aspectos relevantes no ensino "ninguém aprende com aquele que não conhece e ninguém ensina o que não sabe”. (LORENZATO, 2006, p.3).

O reflexo de uma formação frágil é observado nos indicadores de desempenho das avaliações nacionais como a avaliação nacional do rendimento escolar (ANRESC) por meio da prova brasil, parte integrante do sistema nacional de avaliação da educação básica (SAEB). Assim sendo, aponta-se a relevância desta pesquisa em âmbito social, em contraposição às avaliações realizadas que afetam os alunos tendo por foco a aprendizagem, desconsiderando o processo didático.

\section{Discussão e Análise}

A investigação foi norteada pela articulação entre conteúdo e didática, seguindo-se uma abordagem exploratória no espaço de realização da docência envolvendo conteúdos, conceitos, tarefas, debates e análise das situações trabalhadas.

Para que haja aprendizagem em matemática, exige-se trabalhar com pelo menos dois registros simultaneamente, ou seja, o sujeito deve fazer a mudança de enunciado da sentença matemática e fazer o desenvolvimento necessário para construir sua resolução. Portanto, é necessário, segundo Damm (2007), fazer um levantamento dos dados relevantes na sentença dada, identificá-los e montar sua estratégia de resolução.

Os dados desta pesquisa foram registrados numa planilha, pois assim facilitaria aos pesquisadores emitir opiniões quanto ao procedimento e quanto à aprendizagem, e poder-se-ia verificar in loco se estava havendo apropriação quanto ao uso de registros de representação semiótica.

Foram trabalhadas várias atividades envolvendo as estruturas multiplicativas 
vergnausiana elaboradas com o uso de representações semióticas. No entanto, neste artigo, apresentamos apenas uma alguns problemas que foram desenvolvidos em sala de aula com as professoras. No quadro 1, apresenta-se um exemplo de situações de isomorfismo de medidas, no qual foi requerido dos sujeitos fazer, inicialmente, a mudança da representação textual para uma representação numérica e, em seguida, fossem efetuadas as operações de tratamento necessárias para encontrar a solução. Teve-se como objetivo neste tipo de atividade verificar que articulações poderiam ocorrer a partir do registro de partida para o registro de chegada e que significado teria para as professoras essas articulações. Registre-se que esta atividade, representada abaixo, foi elaborada pelas professoras sem a ajuda dos pesquisadores.

\begin{tabular}{|l|l|}
\hline Registro dado em forma de texto & Mudança para representação numérica \\
\hline José tinha cem reais, foi a uma loja, comprou três & Resolução com a ajuda dos pesquisadores. \\
brinquedos, cada um por trinta e dois reais. & {$[100-(3 \times 32)]+32=?$} \\
Repassou para seu irmão um dos brinquedos pelo & Tratamento: $[100-96]+32=4+32=36$. \\
mesmo preço que comprou. Com quantos reais ele & Portanto, José ainda tem $\mathbf{r} \$ 36,00$ \\
ainda ficou? & ou $1 \rightarrow 32$ e $100-?=?$ \\
& $3 \rightarrow ?$ e $?+32=$ \\
\hline
\end{tabular}

Quadro 1: Mudança do registro de partida em linguagem natural para o numérico Fonte: Dados dos pesquisadores (2016).

Todas as professoras demonstraram, inicialmente, insegurança para trabalhar com essa metodologia de ensino, mas perceberam que, usando registros semióticos, em alguns casos, como o da mudança do registro linguagem natural para o registro numérico, ou para outro tipo de representação, poderiam desenvolver vários tipos de sentenças matemáticas e enunciados para o mesmo registro de partida. Este tipo de percepção ajuda o sujeito a pensar antes de construir sua resposta, portanto contribui para desenvolver suas habilidades cognitivas.

Registre-se que algumas professoras apresentaram dificuldades para esboçar o registro de chegada na forma de sentença matemática, ou seja, de expressão numérica. Em geral, elas só sabiam representar o registro de chegada usando estruturas multiplicativas - usando a proporcionalidade -, conforme representado no quadro 2.

$\begin{aligned} 1 & \rightarrow 32 \\ 3 & \rightarrow ? \text { e } 100-?=? ? \text { e } \quad ?+32=36\end{aligned}$

Quadro 2: Resolução usando proporção

Fonte: Dados dos pesquisadores (2016).

Após discussão dos pesquisadores com as professoras a respeito de elaboração de enunciados de problemas, assim como, da construção das resoluções, elas observaram que, com essa dinâmica, aguçaria bastante o pensar matematicamente sobre resolução de problemas, em especial os problemas relacionados à classe de isomorfismos de medidas. 
No quando 3, apresenta-se uma atividade, também referente à classe de isomorfismo de medidas, em que solicitou-se das professoras a elaboração de uma atividade multiplicativa, uma de divisão partitiva e uma de divisão quotitiva, e que em ambas fosse usado como registros de partida a linguagem natural (em forma de textos).

\begin{tabular}{|l|l|l|}
\hline \multicolumn{1}{|c|}{ Multiplicativa } & \multicolumn{1}{|c|}{ Divisão partitiva } & \multicolumn{1}{c|}{ Divisão quotitiva } \\
\hline $\begin{array}{l}\text { Uma caixa de bombom sortido } \\
\text { custa quinze reais. Quanto }\end{array}$ & $\begin{array}{l}\text { Juca pagou por quatro caixas } \\
\text { de bombom oitenta reais. }\end{array}$ & $\begin{array}{l}\text { Elabore um enunciado de problema } \\
\text { para o registro numérico: }(18-6) \div\end{array}$ \\
$\begin{array}{l}\text { custam quatro caixas deste } \\
\text { mesmo bombom? }\end{array}$ & $\begin{array}{l}\text { Quanto custa uma caixa de } \\
\text { bombom? }\end{array}$ & $3=$ ? \\
\hline
\end{tabular}

Quadro 3: Situações de atividades na classe de isomorfismo de medidas Fonte: Dados dos pesquisadores (2016).

$\mathrm{Na}$ atividade multiplicativa, requeria-se a mudança do registro de partida, dado em forma de texto para um registro de chegada em forma de uma representação numérica e depois fizesse o tratamento semiótico da sentença matemática encontrada para chegar ao resultado.

$\mathrm{Na}$ atividade divisão partitiva, requeria-se a mudança do registro de partida dado em forma de texto, também, para um registro numérico e depois desenvolvê-lo para chegar à resposta.

$\mathrm{Na}$ atividade divisão quotitiva, solicitava-se a mudança do registro de partida dado em forma de sentença numérica para um registro de chegada em forma de texto. As construções das resoluções, também foram realizadas pelas professoras, sem a ajuda dos pesquisadores. No entanto, elas demonstraram dificuldades para elaborar o registro de chegada para a atividade de divisão quotitiva. Mas, essas dificuldades apresentadas foram consideradas pelos pesquisadores como uma situação normal, dada a novidade em se trabalhar com este tipo de metodologia de ensino. As construções dos registros de chegada estão representados no quadro 4.

\begin{tabular}{|c|c|c|}
\hline $\begin{array}{c}1 \text { caixa } \rightarrow 15,00 \\
4 \text { caixas } \rightarrow ? \\
4 \times 15=60 \\
\text { Logo } 4 \text { caixas custam } R \$ 60,00\end{array}$ & $\begin{array}{c}4 \text { caixas } \rightarrow 80 \\
1 \text { caixa } \rightarrow ? \\
80 \div 4=20 \\
\text { Logo } 1 \text { caixa de bombom } \\
\text { custa } R \$ 20,00\end{array}$ & $\begin{array}{l}\text { José ganhou de seu tio } 18 \text { bolinhas de } \\
\text { gude, ficou com } 6 \text { e dividiu o } \\
\text { restante com seus } 3 \text { irmãos. Quantas } \\
\text { bolinhas cada um dos seus irmãos } \\
\text { ganhou? }\end{array}$ \\
\hline
\end{tabular}

Quadro 4: Resolução construídas pelas professoras Fonte: Dados dos pesquisadores (2016).

Por outro lado, observou-se com base no quadro referente à atividade divisão partitiva, que o enunciado, elaborado pelas professoras, leva o leitor a fazer várias interpretações do problema, tais como: as caixas eram iguais? eram da mesma marca? tinham a mesma quantidade de bombom? essa foi uma das situações que tivemos de retomar com as professoras, enfatizando os cuidados que elas deveriam ter na elaboração de problemas, para que não deixassem dúvidas ao leitor. 
Da mesma forma, chamou-se a atenção quanto à resolução dada para o problema referente à atividade de divisão quotitiva. Se não for dito que a divisão é em partes iguais, não se refere ao enunciado do problema proposto, uma vez que este se refere a uma divisão em partes iguais, divisão exata (aplicação do algoritmo euclidiano).

Com esses tipos de problemas trabalhados, as professoras puderam constatar a riqueza de detalhes e perceber as dificuldades específicas que cada uma poderia levantar. A escolha de valores numéricos, que transforma um problema relativamente fácil em um problema mais difícil, normalmente, aumenta a curiosidade do aluno. Isso pode encorajá-lo a descobrir outros procedimentos de resolução de problemas.

Para Vergnaud (2007), o ato de ensinar é de alguma forma uma provocação, e como tal, as explicações não são suficientes para que haja aprendizagem e desenvolvimento das competências, pois elas complementam a aprendizagem.

Focando-se nos aspectos cognitivos, na análise, buscou-se também verificar, em cada atividade de matemática desenvolvida, a operação utilizada na resolução e o tipo de situação, as grandezas envolvidas e os valores numéricos envolvidos. Nesse contexto, constatou-se que o conjunto dos problemas elaborados/resolvidos pelas professoras contemplou todas as classes pertencentes à categoria de isomorfismo de medidas, fator relevante para o aprofundamento das competências das professoras envolvidas nessa pesquisa.

\section{Conclusão}

Espera - se que esta pesquisa possa fortalecer o conhecimento didático das professoras partícipes em função da classificação de problemas segundo Vergnaud, e que a elaboração/resolução segundo Duval, no ambiente escolar, possa contribui para enriquecer sua práxis docente, pois a exploração deste material metodológico didático favorece a compreensão e, portanto, o desenvolvimento cognitivo do sujeito.

Além disso, no processo de pesquisa, ao explorar-se a utilização da classe de problemas multiplicativos para elaborar e resolver atividades usando registros semióticos, observou-se que os sujeitos desenvolvem mais habilidades matemáticas, o que lhes permite descobrir novas maneiras de resolver um problema matemático. Observou - se, também, a preocupação das docentes, antes de eleger os dados de uma sentença matemática, como deveriam selecionar e montar uma estratégia de resolução, de forma a poder desenvolver um raciocínio para chegar à resposta. 
Esse fato, segundo Damm (2009), é necessário, pois, quando as informações acerca dos elementos - incógnitas e os números - estão indicados claramente, isto poderá facilitar para que a construção da resposta possa ser executada. Em relação aos problemas multiplicativos, isso ocorre porque se dispõe da mudança de várias representações semióticas.

$\mathrm{Na}$ pesquisa desenvolvida, observou-se que as professoras desenvolveram conhecimento e aprendizagem, os quais, segundo Duval (2011), se o aluno consegue mobilizar, pelo menos, dois registros semióticos e operá-los, é porque houve aprendizagem, fato observado e constatado nesta pesquisa.

Em suma, a pesquisa revela que todos os participantes mostraram-se capazes de trabalhar, com habilidade, a conversão e o tratamento de registros, o que lhes proporcionou o conhecimento de mais uma metodologia, até então, não conhecida por elas. No entanto, vale destacar que não se deve considerar que os problemas da educação serão resolvidos com a mobilização pelo aluno dessa metodologia de ensino. Encare-se, portanto, designar-se, como mais uma alternativa de ensino.

\section{Referências}

BRUNER, J. S. O processo da educação. São Paulo: Nacional, 1978.

CURI, E. A formação matemática de professores dos anos iniciais do ensino fundamental face às novas demandas brasileiras. Revista Iberoamericana de Educación (on line), n. 37/4, pp. 26-46, jan, 2006.

DAEP/INEP. Resultado SAEB, instituto nacional de estudos e pesquisas educacionais Anízio Teixeira - Inep, 2015. Disponível em www.inep.gov.br/resultados - 2015. acesso em: 2015.

DAMM, R. F. Representação, compreensão e resolução de problemas aditivos. In: MACHADO, S. D. A. (Org.). Aprendizagem em matemática: registros de representação semiótica. $3^{\mathrm{a}}$ ed. Campinas/SP: Papirus, 2007, p. 35-47.

Educação Matemática: uma (nova) introdução. In: MACHADO, S. D. A. (Org.). Registros de representação. $3^{a}$ ed. Revista. São Paulo: Educ, 2009, p. 167-188.

DUVAL, R. Registro de representação semiótica e funcionamento cognitivo da compreensão em matemática. In: MACHADO, S. D. A.(Org.). Aprendizagem em matemática: registros de representação semiótica. $3^{\mathrm{a}}$ ed. Campinas/SP: Papirus, 2007, p.11-33.

Semiósis e pensamento humano: registros semióticos e aprendizagens intelectuais. Tradução: Lênio Fernandes Levy e Maria R. A da Silva. ${ }^{\text {a }}$ ed. São Paulo/SP: Editora Livraria da Física, 2009.

. Ver e ensinar a matemática de outra forma - entrar no modo matemático de pensar: os registros de representações semióticas. Organização: Tânia, M. M. Campos. Tradução: Marlene Alves Dias. $1^{\text {a }}$ ed. São Paulo: PROEM, 2011. 
GASPARIN, J. L. Aprender, desaprender, reaprender. 2005. texto digitalizado

GITIRANA, V.; et al. Repensando a multiplicação e a divisão: contribuições da teoria dos campos conceituais. Ed. PROEM Ltda., São Paulo, 2014.

LORENZATO, S. Para aprender matemática. Campinas/SP: autores associados, 2006. MAGINA, S. M. P. et al. Repensando adição e subtração: contribuições da teoria dos campos conceituais. Ed. PROEM Ltda. São Paulo, 2001.

MORETTI, M T. A translação como recurso no esboço de curvas por meio de interpretação global de propriedades figurais. In: MACHADO, S. D. A.(Org.). Aprendizagem em matemática: registros de representação semiótica. $3^{a}$ ed. Campinas/SP: Papirus, 2007, p.149-160.

NERES, R. L.; ELIZIANE, R. C.; JOSÉ, C. M. Mathematics in the initial years of fundamental teaching in brazil: an experience with teachers in training in the pedagogy course. Creative Education, USA, n. 8, pp. 607-626, april, 2017.

OTERO, M. R.. La notion de situation: analysée depuis la théorie des champs conceptuels, lathéorie des situations, la dialectique outil-object et la théorie anthropologique du didactique. Rev. Electrón. Investig. Educ. Cienc. [online]. vol.5, n.1, pp. 42-53, 2010.

OTERO, M. R. La Teoria de los Campos Conceptuales de Gerárd Vergnaud. In: OTERO, M. R. et al. (Org). La Teoria de los Campos Conceptuales y la conceptualización en el aula de matemática y física. Buenos Aires: Dunken. pp.15-31, 2014.

PERRENOUD, P. A prática reflexiva no ofício de professor: profissionalização e razão pedagógica. Porto Alegre: ARTMED, 2002.

PESSOA, C.; BORBA, R. Quem dança com quem: o desenvolvimento do raciocínio combinatório de crianças de $1^{\mathrm{a}}$ a $4^{\mathrm{a}}$ série. Zetetiké-revista de educação matemática, v.17, n. 31, pp.105-150, janeirojunho, 2009.

VALE, I; PIMENTEL, T.; BARBOSA, A. Ensinar matemática com resolução de problemas. Quadrante - revista de investigação em educação matemática, Lisboa/Portugal, v. XXIV, n.2, pp. 40-60, 2015.

VERGNAUD. G. Teoria dos campos conceituais. In Nasser, 1. (ed.) anais do $1^{\circ}$ seminário internacional de educação matemática do rio de janeiro, pp. 1-26, 1993.

A teoria dos campos conceituais. In: BRUN, JEAN (dir.). didácta das matemáticas. Trad. Maria José Figueiredo. Lisboa: Instituto Piaget, pp. 155-191, 1996.

- ¿Enqué sentido la teoría de los campos conceptuales puede ayudarnos para facilitar aprendizaje significativo? Investigações em ensino de ciências, v.12, n. 2, pp. 285-302, 2007.

A criança, a matemática e a realidade: problemas do ensino da matemática na escola elementar. Curitiba: Ed. da UFPR, 2009.

A matemática além dos números. Revista Pátio, ano 4, n. 13, p. 25, junho-agosto 2012. Entrevista concedida à prof ${ }^{\mathrm{a}}$. Katia Regina Ashton Nunes.

WALL, E. S. Teoria dos Números para professores do ensino fundamental. Tradução: Roberto Cataldo Costa. Porto Alegre: AMGH, 2014. 